\title{
Epigenética computacional: simulación de mecanismos de adquisición de resistencia a fármacos en cultivos celulares
} Marina Pérez-Aliacar ${ }^{1}$, Jacobo Ayensa-Jiménez ${ }^{1}$, Mohamed H. Doweidar ${ }^{2}$, Manuel Doblaré ${ }^{1}$

${ }^{1}$ Tissue Microenvironment Lab (TMELab), I3A, Universidad de Zaragoza

${ }^{2}$ Applied Mechanics and Bioengineering (AMB) , I3A, Universidad de Zaragoza

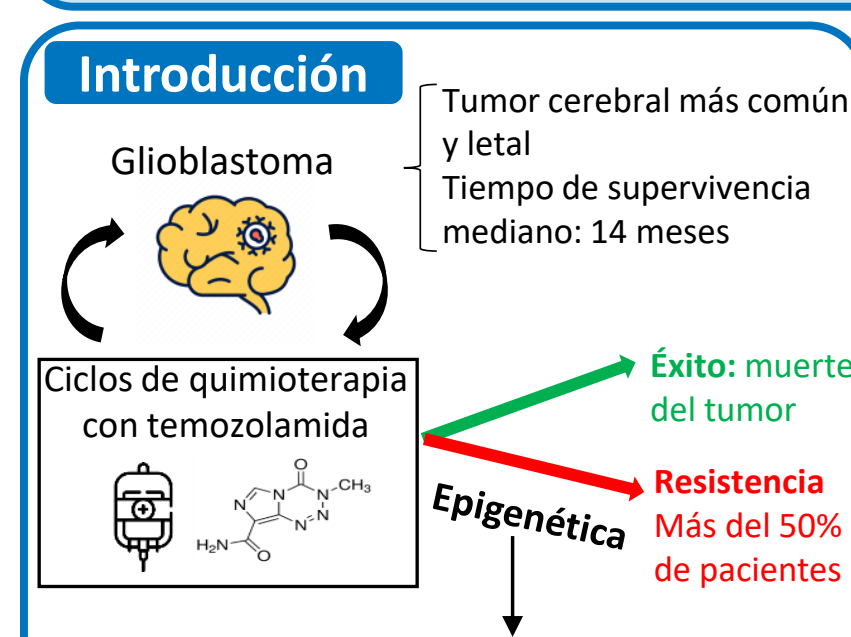

Cambios heredables en la expresión génica que no derivan de una modificación en el ADN

Objetivo: modelar cambios epigenéticos

\section{Conclusiones}

Modelo inspirado en la mecánica de medios continuos para modelar cambios epigenéticos

- Reproducción in silico de fenómenos de adaptación celular, como la adquisición de resistencia a fármacos

Un buen modelo es crucial para obtener resultados que reproduzcan la realidad

\section{Modelo matemático}

Células

$\frac{\partial C_{n}}{\partial t}=\underbrace{\frac{1}{\tau_{\mathrm{gr}}^{0}} \Psi_{\mathrm{gr}}(R) F_{\mathrm{gr}}\left(C_{n}, C_{d}\right) C_{n}}_{\text {Crecimiento }}-\underbrace{\frac{1}{\tau_{\mathrm{ap}}^{0}} \Psi_{\mathrm{ap}}(R) \Pi_{\mathrm{ap}}(T) C_{n}}_{\text {Muerte }}$
$\frac{\partial C_{d}}{\partial t}=\frac{1}{\tau_{\mathrm{ap}}^{0}} \Psi_{\mathrm{ap}}(R) \Pi_{\mathrm{ap}}(T) C_{n} \underbrace{\text { Nor }}_{\text {Necróticas }}$

Especie química - Temozolamida (TMZ)

$\frac{\partial T}{\partial t}=S-k T$

Variable Interna - Resistencia

$$
\frac{\partial R}{\partial t}=\mathbb{I}_{\{R \leq 1\}}\left(\Theta \cdot \mathbb{I}_{0}(\Phi) \mathbb{I}_{\mathbb{R}^{+}}\left(\frac{\partial T}{\partial t}\right)+\beta \frac{1}{\tau_{\mathrm{gr}}^{0}} \Psi_{\mathrm{gr}}(R) F_{\mathrm{gr}}\left(C_{n}, C_{d}\right) R\right)
$$

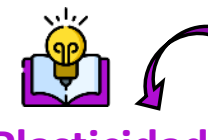

Plasticidad Adquisición de resistencia

Herencia

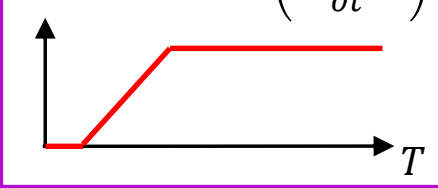

Superficie de fluencia: $\mathbb{I}_{0}(\Phi(T))$

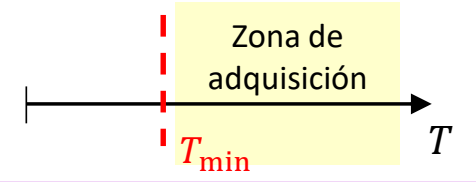

\section{Resultados}

Simulación esferoide

20 días

$4 \cdot 10^{6}$ células

$\overrightarrow{\mathrm{g}}_{10} \times 10^{6}$

Células con TMZ

8 Control

6

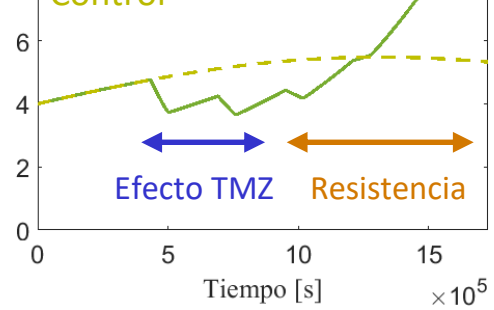

¿Y si no se tiene en cuenta la resistencia?

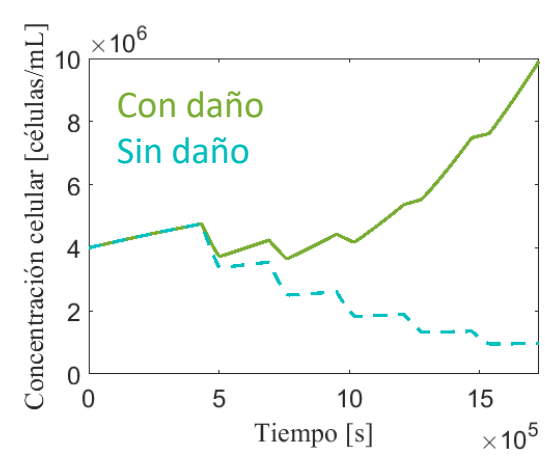

ipótesis

TMZ incrementa muerte celular

Las células resistentes mueren menos y proliferan más
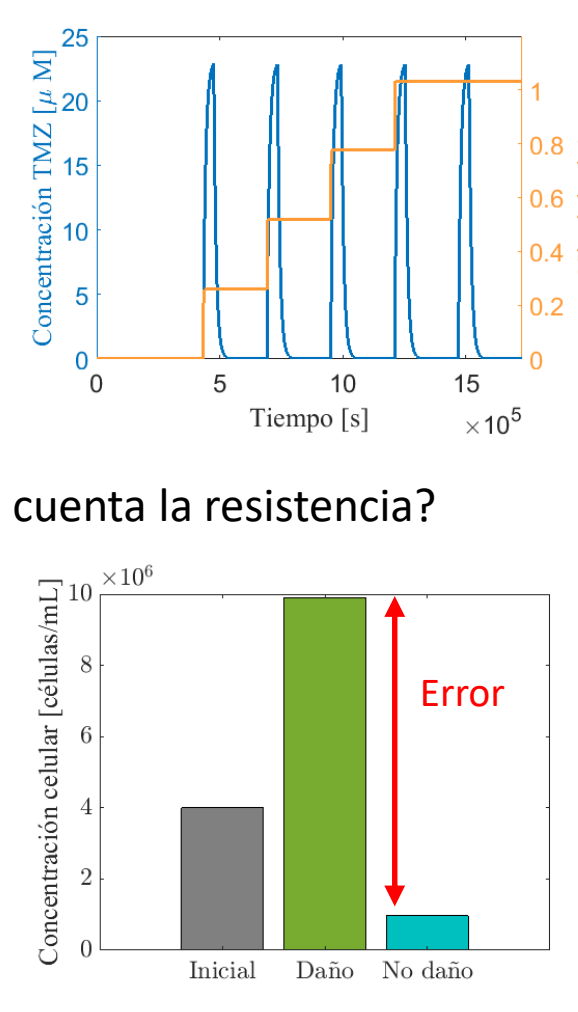